\title{
DESIGNING PRODUCTS WITH A FOCUS ON SELF- EXPLANATORY ASSEMBLY, A CASE STUDY
}

\author{
Parmentier, Davy Daniël (1); Detand, Jan (1); Saldien, Jelle (1,2)
}

1: Department of Industrial Systems Engineering and Product Design, Ghent University; 2: IMECMICT-Ghent University

\begin{abstract}
Designing products with a focus on self-explanatory assembly can reduce the use of procedural instructions and the associated problems. This paper describes how different groups of students, in two different design-engineering courses designed or redesigned products in an attempt to make the assembly of the product self-explanatory. The design outcomes are discussed in relation to the design context and linked to existing theory on design for meaning.
\end{abstract}

Keywords: Industrial design, Industry 4.0, Case study

Contact:

Parmentier, Davy Daniël

Ghent University

Department of Industrial Systems Engineering and Product Design

Belgium

davy.parmentier@ugent.be

Cite this article: Parmentier, D.D., Detand, J., Saldien, J. (2019) 'Designing Products with a Focus on Self-Explanatory Assembly, a Case Study', in Proceedings of the 22nd International Conference on Engineering Design (ICED19), Delft, The Netherlands, 5-8 August 2019. DOI:10.1017/dsi.2019.214 


\section{INTRODUCTION}

When assembling products, procedural instructions are very often used to explain the assembly process. However, these instructions suffer from some important drawbacks when using them. First, they oblige the assembler to divide attention between instructions and the product, forcing mental integration of information, which increases cognitive load. This effect is called the split-attention effect (Sweller et al., 1998). From a work-motivation point of view secondly, procedural instructions could induce negative effects because they leave no or limited opportunities for autonomous decision making. The need for autonomy is an innate psychological need linked to mental well-being and selfmotivation (Ryan and Deci 2000; Gagné and Deci 2005). Not leaving any autonomy could have a detrimental effect on work motivation during the assembly of the product. Another drawback is that these types of instructions are hardly used. When considering operators in industry, sometimes up to $60 \%$ of all tasks are performed based on own experience (Fast-Berglund et al., 2013). Also, many information in the instructions is not used or considered important by operators (Johansson et al., 2017). Following, when the action seems to be clear, people do not consult the instructions. In a use context, designers consider how meaning on the use is constructed and how the user subsequently will interact with their products. However, how end-users or operators construct meaning for assembly, when interacting with components and subassemblies, is hardly or not considered. Nevertheless, designers have an impact on how components and subassemblies are perceived and interpreted, and have a responsibility towards end-users or operators assembling their products. During assembly, people interact and give meaning to what they perceive or experience. How components and subassemblies are perceived is therefore relevant to support the assembly process. Affordances (i.e., action possibilities, see Gibson $(1977,1979)$ ) and product semantics (i.e., meanings associated with product features) are important when considering design for meaning (DFM). See, e.g., Norman $(1988,1999)$ for affordances in product design, and Krippendorff and Butter (1984) and Krippendorff (1989) on product semantics. For the applications of both concepts in product design see You et al. (2007). Considering, with a focus on intuitive assembly, these affordances and product semantics for connections, components and subassemblies could potentially make the assembly more selfexplaining. To assemble a product, it is important to perceive the required action possibilities or affordances when needed and to be discouraged to engage in actions not supporting correct assembly. Product semantics could change the affordance perception and guide the assembler during the assembly process. Depending on the polarity of the affordance (i.e., affordances can be positive or negative (Gibson, 1979)), the affordance types described by Gaver (1991) (i.e, perceptible affordances, hidden affordances, false affordances and correct rejections) can be considered and altered. Gaver separated the affordance itself from its perception resulting in these four types: false affordances (FA's, i.e., non-existing action possibilities but perceived as possible), hidden affordances (HA's, i.e., imperceptible action possibilities), perceptible affordances (PA's, i.e., perceptible action possibilities) and correct rejections (CR's, i.e., correctly rejected, non-existing and non-perceptible action possibilities). Research is needed to understand how affordances and product semantics are used by product designers when focusing on meaning during assembly. Boess (2008) interviewed designers on meaning in product use. The interview indicated that designers especially follow their own intuition when they design for product meaning. Questions arise whether this intuition is based on prior knowledge or experience and if meaning during assembly is also considered intuitively. Exploratory case studies where future designers (e.g., students) are asked to design and redesign products in a way that the assembly process of these products becomes self-explaining can potentially offer such insights (e.g., insights on how solutions and remaining problems can be linked to existing affordance theory and product semantics). The results can also indicate the quality of the intuitive approach in an assembly context (e.g., are all crucial affordances identified and is the assembly self-explaining). Following, the results can indicate whether a more formal method to consider meaning in assembly is needed. In this paper we will discuss two case studies where students designed or redesigned products, considering the self-explanatory aspect of the assembly. The solutions found by the students in a design and redesign context are linked to affordances and product semantics and discussed within these contexts. In the following sections we will describe the method used and the results of the case studies. 


\section{METHOD}

Both case studies were performed with Bachelor of Science (BSc) students that did not receive any courses on affordance theory or product semantics and subsequently did not have any prior knowledge concerning these theories. To let the students consider how meaning could be constructed, they were shown some examples from the book "the Psychology of Everyday Things" (Norman, 1988). Images were used illustrating natural mapping (e.g., a kitchen stove where the controls are arranged in the same manner as the burners, illustrating which control operates which burner), semantic and physical constraints (e.g., a Lego Police Motorcycle where physical constraints limit wrong placements of parts and where semantics indicate correct positioning, e.g., head in normal position on the body, etc.). The images were shown without additional information, thus allowing the students to give meaning to what they perceived and allowing them to consider how meaning was promoted. Affordances and product semantics were not explained nor did they receive a framework, method or technique to analyse, consider, classify or alter affordances or product semantics on a component or subassembly level in order not to compromise the intuitiveness of the solutions found. Subsequently, the results could potentially confirm that affordances and product semantics can be considered and altered intuitively to promote assembly meaning, without explicitly knowing any terms or theories. Differentiating the case-studies so one group redesigns a product and another group designs a product from scratch could possibly induce different results or different attention points. Following, the case studies aim to answer the following research questions.

- RQ1: Do future designers (i.e., students) intuitively consider affordances and product semantics without even knowing these terms when focusing on self-explanatory assembly?

- RQ2: Do future designers (i.e., students) intuitively consider different solutions to make the assembly self-explaining when they have to design a product from scratch compared to redesigning a product?

\subsection{Case study 1: redesigning a product}

In this first case-study, products were designed and then redesigned to make the assembly of the product self-explaining. This case-study gives insights on the changes that students implemented intuitively when focusing on self-explaining assembly during the redesign of a product. In this casestudy also two prototypes (i.e., one of the initial design and one of the adapted design) were created, allowing the comparison of the prototypes and the assembly process.

\subsubsection{Course and participant description}

The course ( 6 credits, 180 hours of study time for every student) was scheduled in the first semester of the second year. Participants were 42 students from the second year Bachelor of Science (BSc) program in Industrial Design Engineering Technology and from the second year Bachelor of Science (BSC) program in Electromechanical Engineering Technology of the university where this study took place.

\subsubsection{Design assignment}

During a 12 week assignment, the students designed and prototyped a product that could be produced by using simple hand tools and machines. The product needed to be designed so it could be transported flat pack and needed to have at least 3 different types of wood joints, produced with the necessary precision. The students also had to design and produce jigs and tools that helped them in controlling their hand tools and machines so they were able to produce small series of their product within the required tolerances. Also procedural assembly instructions were designed and everything needed to be finalised by the end of week 8 . In week 9 the students received the new assignment to redesign the product so the assembly would become self-explaining. The assembly structure and the number of components had to remain the same.

\subsubsection{Procedure}

The participants were randomly divided in design teams of 2 to 3 students, finally resulting in 15 design teams, all designing a different product. Every week they received consult on their progress and prototypes. In week 9, when given the extra assignment, they were shown the examples of natural 
mapping, semantic and physical constraints. The students also produced a final image of the product that informed the users of the end result. After the redesigns were finished, the results were presented and compared (i.e., the solutions with the external instructions and with the integrated instructions). Different students who had no prior knowledge of the product to be assembled, were asked to assemble the prototypes in order to compare the assembly process of the 2 products.

\subsection{Case study 2: designing a new product}

In this second case-study, products were designed with a focus on making the assembly selfexplaining from the beginning. The product had two different functions and needed to be assembled and disassembled to use the other function. In this context it is not preferable to consult a manual, the assembly of the product must be as self-explaining as possible. Insights on solutions that were found intuitively to make the assembly self-explaining when designing from scratch were gathered.

\subsubsection{Course and participant description}

The course ( 6 credits, 180 hours of study time for every student) was scheduled in the second semester of the third year from the Bachelor of Science (BSc) program in Industrial Design Engineering Technology of the university where this study took place. Participants were 27 third year academic bachelor students (19 male and 9 female) studying industrial design engineering courses.

\subsubsection{Design assignment}

During a 12 week assignment the students designed a product that could be disassembled and reassembled into another product with a different function. They had to reuse all the components of the first configuration in the second configuration and design their product so the two assemblies could be assembled without requiring prior knowledge or instructions. They also had to consider how their design would change when produced in different batch sizes.

\subsubsection{Procedure}

The participants were divided in design teams of 3 students, so finally 9 products were designed by these teams. The first weeks of this assignment were similar to other design assignments. Students started brainstorming on their products, sketching ideas, making first prototypes and iterating on these prototypes. Also in this case study they could receive a consult every week. In contrast to the first case study, the focus on a self-explaining assembly was set and the examples of natural mapping, semantic and physical constraints were shown in the first week. The solutions found by the teams were tested with users and used to optimise their product. The teams prototyped their product and demonstrated how it should be assembled and disassembled in the two configurations. They also made reports on their work.

\subsection{Evaluation method for the case-studies}

Affordances and product semantics are important theories when considering meaning in product design. Therefore, affordances and product semantics were considered for both case studies to evaluate the changes made (i.e., in case study 1) or the solutions implemented (i.e., in case study 2). Such an evaluation was made for both case-studies on affordances (i.e., if constraints were added or removed, changing the action possibility) or on product semantics (i.e., if perceptual cues were added or removed changing the meaning of the product features). Adding or removing constraints can make an undesired assembly connection impossible or can facilitate a desired assembly connection. Perceptual cues can highlight a desired assembly connection, making an undesired assembly connection imperceptible, e.g., by the mechanism of affordance threshold. Lu and Cheng (2013) presented the affordance threshold where, due to the competitiveness of affordance perception, a change in the perceptual state of an affordance can reduce its own, or increase the threshold of another affordance. In the first case study the changes were evaluated from the prototypes (e.g., semantic changes) and from the assembly process of these prototypes (e.g., difficulties that occurred, time needed to assemble,...). Both assemblies were filmed, analysed and compared. Difficulties were, when possible, linked to the affordances: e.g., wrong assembly due to undesired but perceptible affordances (PA's), not knowing how to assemble correctly due to desired but hidden affordances (HA's), or thinking to 
know how to assemble but not being able to assemble due to false affordances (FA's). The polarity of the affordance (Gibson, 1979) and the types according to the classification made by Gaver (1991) in FA's, PA's, HA's or CR's, were considered in relation to the semantic triggers. Other changes like clustering of components (e.g., components to be assembled in one assembly step are grouped together) and spatial cueing (e.g., components arranged according to the assembly sequence and their position in the assembly), see the work of Kirsh (1995), were also registered. The solutions found in the second case study were also evaluated on the constraints that were applied in relation to desired and undesired affordances (i.e., again polarity of the affordance) and the semantic triggers applied. This evaluation was based on the prototypes and the reports of the design teams.

\section{RESULTS}

\subsection{Case study 1}

Figure 1 gives an overview of the products designed during case study 1 . The changes made by the students, when comparing the redesigned products with the initial products, are summarized in Table 1.

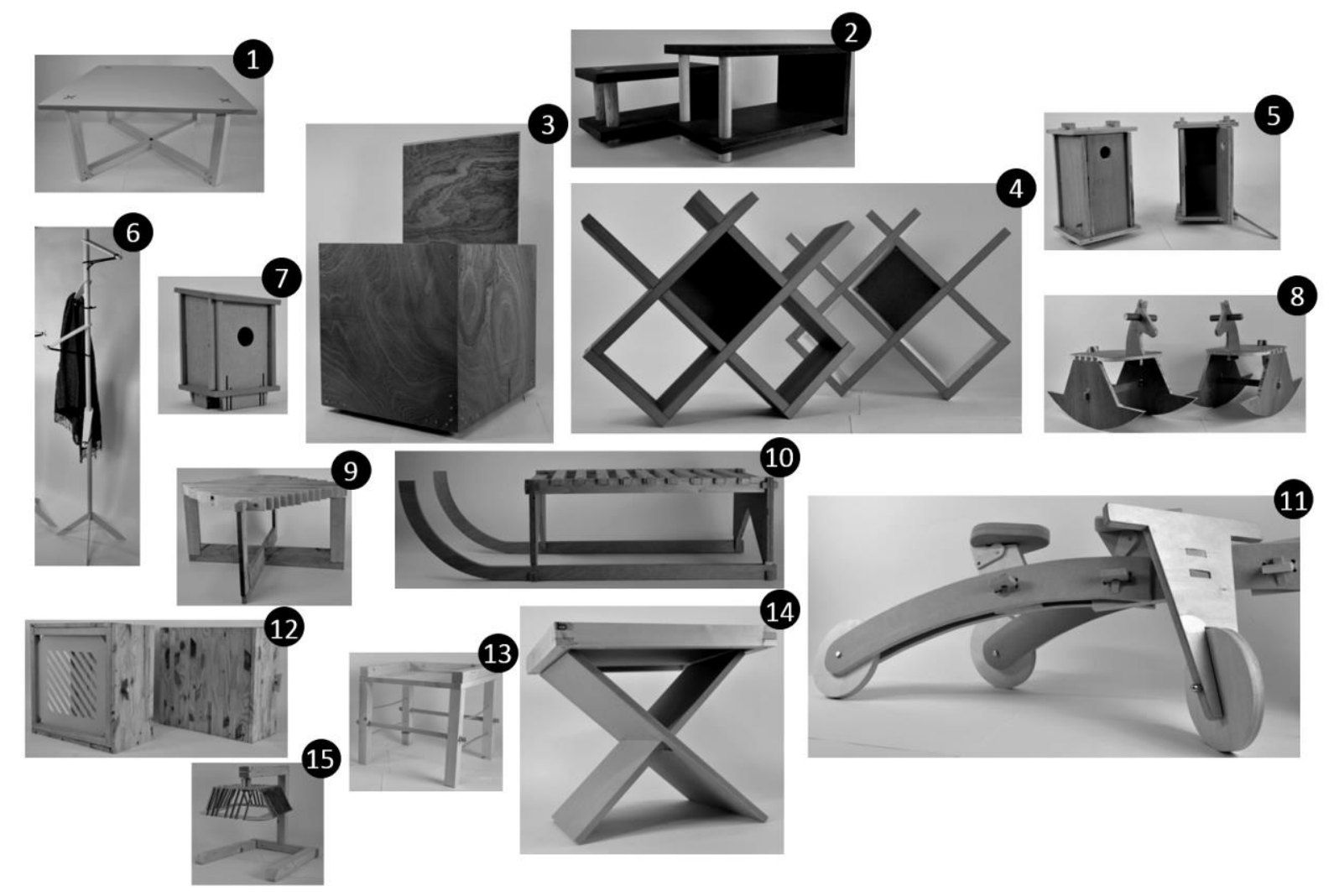

Figure 1. Products designed and redesigned in case study 1: (1) coffee table / (2) coffee table / (3) storage box / (4) DVD rack / (5) bird house / (6) Coat rack / (7) bird house / (8) rocking horse / (9) coffee table / (10) sled / (11) bicycle / (12) computer case / 13) coffee table /

(14) coffee table / (15) Light fixture

None of the groups reconsidered the connections themselves or constraints linked to these connections. Nearly all changes made in this first case study were semantic changes, where students added marks, coloured marks or numbers (abbreviated as $\mathrm{M}, \mathrm{CM}$ and $\mathrm{N}$ in Table 1) on component features, linking components and connections to one-another (e.g., by giving contact surfaces of connections a similar colour, mark or number). Considering these kinds of adaptations one could say that the desired connection was not clear to the assembler and needed to be highlighted. The affordance of correct assembly was hidden and by adding these marks it became perceptible. However, these kind of solutions do not change the other affordances. When these semantic triggers are noticed by the assembler, they also hide other undesired affordances by the mechanism of Affordance Threshold (abbreviated as AT in Table 1). Nevertheless, many of these assemblies still suffer from negative perceptible affordances (i.e., undesired, perceptible action possibilities, illustrated 
as - PA's in Table 1) which can cause assembly errors. Product 1, illustrated in Figure 1, is such an example: each table leg can be placed in the table top in 4 different ways, but only 1 way is correct. There are already 3 negative PA's in this connection alone, illustrating that this product has many negative PA's remaining, as reported in Table 1 . When clustering of components (CL in Table 1) and spatial cueing (SC in Table 1) were used is also reported in Table 1. However, these solutions were not always clear to the assembler (e.g., components clustered in a package were unpacked and arranged on the table, losing the clustering). Some teams found the assembly of their product already very intuitive and did not make any changes (e.g., the coat rack in Figure 1). This product has components that have a clear function and orientation, clarifying the assembly. Remarks were also made concerning the comparison of the two assemblies (i.e., the initial product with procedural instructions and the redesigned product without the procedural instructions). Measurement of the assembly time was due to some limitations (see the discussion), but remarks (in Table 1) were also made when considered relevant.

Table 1. Solutions implemented and problems remaining in case study 1

\begin{tabular}{|c|c|c|c|c|}
\hline \multicolumn{5}{|c|}{$\begin{array}{c}\text { Abbreviations used: } \mathrm{P}=\text { Product } / \text { - PA's }=\text { Undesired Perceptible Affordances } / \mathrm{M}=\text { Marks } / \mathrm{C} \mathrm{M}= \\
\text { Coloured Marks } / \\
\mathrm{N}=\text { Numbering } / \mathrm{AT}=\text { Affordance Threshold } / \mathrm{CL}=\text { clustering } / \mathrm{SC}=\text { Spatial Cueing }\end{array}$} \\
\hline $\mathbf{P}$ & Changes & & $\begin{array}{l}\text { Problems } \\
\text { Remaining }\end{array}$ & Remarks \\
\hline 1 & M & AT & Many - PA’s & $\begin{array}{l}\text { - PA's cause errors in the assembly without the } \\
\text { procedural instructions. }\end{array}$ \\
\hline 2 & M & AT & - PA's & $\begin{array}{l}\text { Assembly with instructions is more efficient. } \\
\text { Repositioning is unclear without instructions. }\end{array}$ \\
\hline 3 & $\mathrm{CM}$ & AT & Many - PA’s & $\begin{array}{l}\text { Assembly sequence was different and lead to error in the } \\
\text { assembly without procedural instructions }\end{array}$ \\
\hline 4 & $\mathrm{CM}$ & AT & None identified & $\begin{array}{l}\text { Assembly sequence was different, but no measurable } \\
\text { difference in assembly time. }\end{array}$ \\
\hline 5 & $\mathrm{~N} / \mathrm{CL}$ & AT & Many - PA’s & $\begin{array}{l}\text { Both assemblies suffered from - PA's. The assembly } \\
\text { with the instructions was more efficient. }\end{array}$ \\
\hline 6 & none & & None identified & $\begin{array}{l}\text { Easy product, every component has a clear distinctive } \\
\text { function and orientation. }\end{array}$ \\
\hline 7 & $\mathrm{CM} / \mathrm{N}$ & AT & None identified & Well designed, clear semantic solutions \\
\hline 8 & none & & - PA's: & $\begin{array}{l}\text { The position of some parts is clear due to the figurative } \\
\text { aspect (i.e., a horse) of the product, others are not. }\end{array}$ \\
\hline 9 & $\mathrm{CL} / \mathrm{SC}$ & & None identified & $\begin{array}{l}\text { Shorter assembly time when assembling without the } \\
\text { instructions. However, the procedural instructions were } \\
\text { hardly used due to the clear conceptual model. }\end{array}$ \\
\hline 10 & none & & None identified & $\begin{array}{l}\text { No significant differences in assembly time between the } \\
\text { two assemblies. }\end{array}$ \\
\hline 11 & none & & None identified & $\begin{array}{l}\text { Shorter assembly time when assembling without the } \\
\text { instructions. Assembly sequence was different. }\end{array}$ \\
\hline 12 & $\begin{array}{l}\mathrm{N} / \mathrm{CL} / \\
\mathrm{SC}\end{array}$ & AT & None identified & $\begin{array}{l}\text { Shorter assembly time when assembling without the } \\
\text { instructions. Numbering, Clustering, and spatial cueing } \\
\text { was clear. }\end{array}$ \\
\hline 13 & $\begin{array}{l}\mathrm{CL} / \mathrm{SC} / \\
\mathrm{N}\end{array}$ & & $\begin{array}{l}\text { Numbering of } \\
\text { the packaging } \\
\text { was unclear. }\end{array}$ & $\begin{array}{l}\text { User unpacked everything without considering. No } \\
\text { measurable difference between the two assemblies. }\end{array}$ \\
\hline 14 & $\mathrm{CL}$ & & None identified & $\begin{array}{l}\text { Shorter assembly time when using the instructions. } \\
\text { Assembly sequence was different. }\end{array}$ \\
\hline 15 & none & & Many - PA's & $\begin{array}{l}\text { With a clear image of the end-result it was possible to } \\
\text { correctly reject the - PA's. The level of this prototype } \\
\text { was detrimental to allow correct evaluation. }\end{array}$ \\
\hline
\end{tabular}




\subsection{Case study 2}

Figure 2 gives an overview of the products and Table 2 summarizes for these products (i.e., the numbers in the left column of Table 2 ) the solutions implemented and the remaining problems.

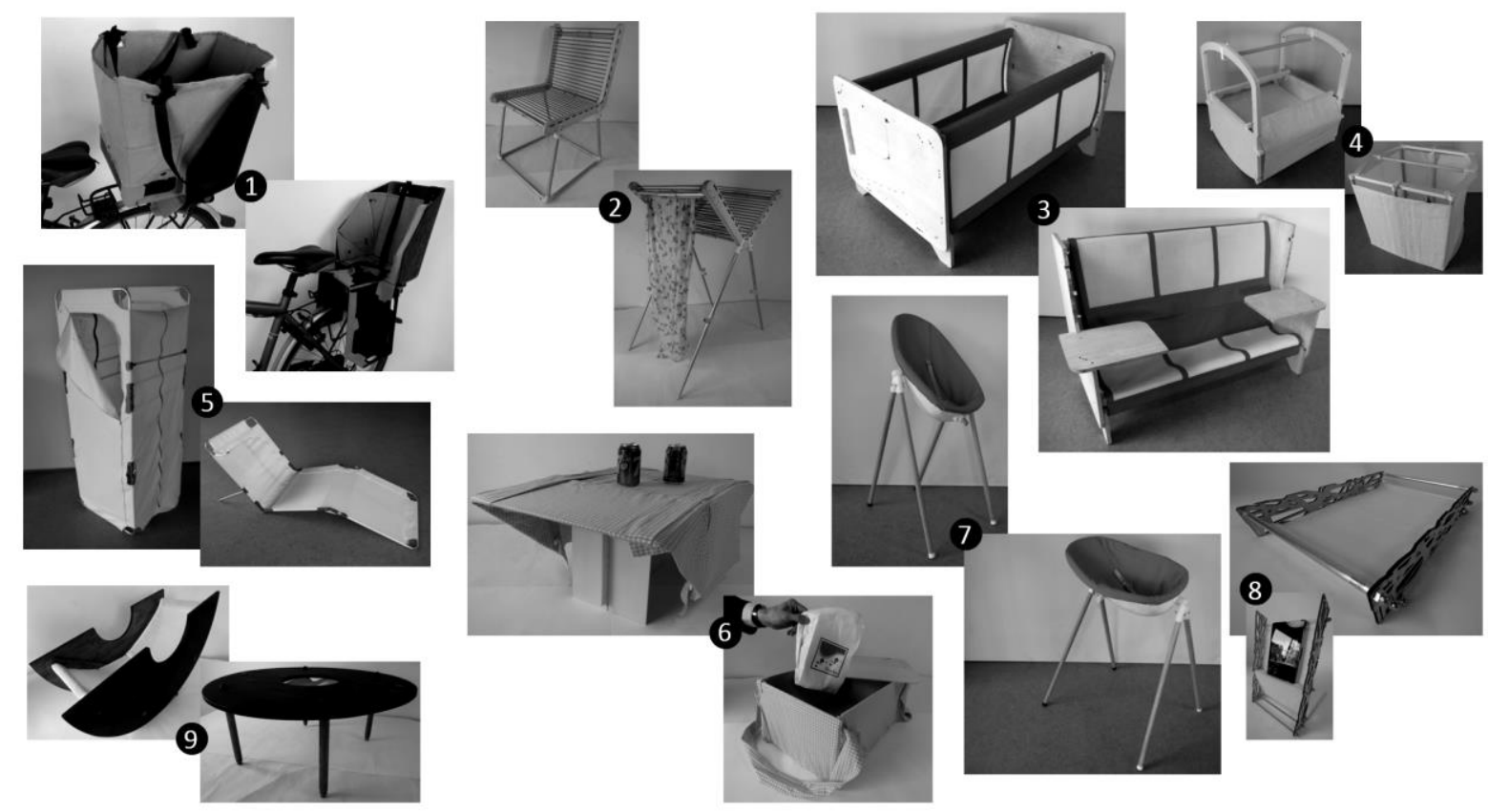

Figure 2. Products designed in case study 2: (1) bicycle seat - basket / (2) chair- clothes horse / (3) bed - bench / (4) cradle - cot / (5) Beach changing room - 2 loungers / (6) Picnic table - picnic basket / (7) Baby seat - swing / (8) Tray - tablet or book support / (9) Rocking chair - Blackboard drawing table for children

Like in case study 1 , the students clearly considered product semantics (i.e., by means of the semantic triggers reported in Table 2) to highlight the desired actions. However, most of these teams also considered how physical constraints could facilitate desired actions (e.g., in product 1, as reported in Table 2, folding lines were added in the felt to facilitate the desired fold position) or how they could avoid undesired actions (e.g., by using a hook and loop fastener connection in product 1, it becomes impossible to connect the two identical parts, which is also correctly rejected by the user). In this case study solutions, similar to the solutions in case study 1 , were found to make hidden affordances perceptible (e.g., in product 6, illustrated in Figure 2, coloured marks were used to link components to one-another), facilitating desired and avoiding undesired actions through the mechanism of affordance threshold. Also solutions changing negative perceptible affordances into false affordances or correct rejections were found (e.g., product 6 , inserting the boards from the wrong side in the textile was made impossible). Nevertheless, also in these products difficulties during assembly remain. Some examples are given in Table 2 under problems remaining, e.g., not knowing the assembly sequence or how to start the assembly, not perceiving the desired potential actions (i.e., hidden affordances), etc. From the user-tests it also came forward that flexible materials are sometimes more complex to assemble correctly, even when semantics are applied. Flexible materials can be manipulated in multiple ways, making it harder to perceive the desired position. These materials can relate in more ways to other components than other rigid components. 
Table 2. Solutions implemented and problems remaining in case study 2

\begin{tabular}{|c|c|c|c|}
\hline No. & Semantic triggers & Constraints & Problems remaining \\
\hline 1 & $\begin{array}{l}\text { Shapes, colour marks on } \\
\text { connections, folding lines } \\
\text { in the felt. }\end{array}$ & $\begin{array}{l}\text { Folding lines in the felt, } \\
\text { different connectors and male } \\
\text { - female connectors (hook and } \\
\text { loop fastener and push- } \\
\text { buttons) }\end{array}$ & $\begin{array}{l}\text { Hidden affordances, the assembly } \\
\text { sequence is unclear. }\end{array}$ \\
\hline 2 & Shapes (e.g., grooves) & Connections, grooves & None identified \\
\hline 3 & $\begin{array}{l}\text { Colour marks on the } \\
\text { connections }\end{array}$ & $\begin{array}{l}\text { The textile constraints the } \\
\text { potential positions of the bars. }\end{array}$ & Assembly sequence unclear. \\
\hline 4 & $\begin{array}{l}\text { Colour marks on the } \\
\text { connections }\end{array}$ & $\begin{array}{l}\text { Connection types (e.g., } \\
\text { clipping connection clips only } \\
\text { in one direction) }\end{array}$ & $\begin{array}{l}\text { Semantics not always clear to the } \\
\text { user especially when installing the } \\
\text { textile: hidden affordance. } \\
\text { Illustrations of the end-product are } \\
\text { mandatory }\end{array}$ \\
\hline 5 & $\begin{array}{l}\text { Shapes (e.g., length of the } \\
\text { tubes, angles that can be } \\
\text { set.) }\end{array}$ & $\begin{array}{l}\text { Connection pieces with } \\
\text { constraints: fixed angles in } \\
\text { both directions. }\end{array}$ & $\begin{array}{l}\text { The frame construction and the } \\
\text { connections used are semantically } \\
\text { clear. Orientation, positioning and } \\
\text { fixating of the textile is difficult to } \\
\text { understand: hidden affordance. }\end{array}$ \\
\hline 6 & $\begin{array}{l}\text { Colour marks on the } \\
\text { connections. Use of well- } \\
\text { known fixations: buttons. } \\
\text { Shapes: size and length of } \\
\text { the grooves in the } \\
\text { wooden boards. }\end{array}$ & $\begin{array}{l}\text { Boards can only be inserted } \\
\text { from certain sides into the } \\
\text { textile. Grooves in het wooden } \\
\text { boards only fit in one-another. }\end{array}$ & $\begin{array}{l}\text { Orientation, positioning and fixating } \\
\text { of the textile is more difficult to } \\
\text { understand. Assembly sequence is } \\
\text { unclear. Semantic triggers for one } \\
\text { function can cause contradiction and } \\
\text { confusion during the other } \\
\text { assembly: negative perceptible } \\
\text { affordances. }\end{array}$ \\
\hline 7 & $\begin{array}{l}\text { Shapes (e.g., length of the } \\
\text { legs are according to the } \\
\text { function.) }\end{array}$ & $\begin{array}{l}\text { Connection with integrated } \\
\text { constraints, allowing freedom } \\
\text { when installed as a swing, } \\
\text { constraining the movement } \\
\text { when installed as a seat. }\end{array}$ & None identified \\
\hline 8 & $\begin{array}{l}\text { Semantically, by creating } \\
\text { a convention. (i.e., } \\
\text { different cut-outs to use } \\
\text { for the two different } \\
\text { functions) }\end{array}$ & None identified & $\begin{array}{l}\text { Knowing the convention is } \\
\text { mandatory. } \\
\text { Negative perceptible affordances } \\
\text { e.g., incorrect installation of the legs } \\
\text { of the bookstand. }\end{array}$ \\
\hline 9 & $\begin{array}{l}\text { Shapes (e.g., the diameter } \\
\text { sizes on the end of the } \\
\text { legs illustrate the } \\
\text { assembly sequence) }\end{array}$ & None identified & None identified \\
\hline
\end{tabular}

\section{DISCUSSION}

Reconsidering RQ1, one can state that the students were able to intuitively consider affordances and product semantics when focusing on self-explanatory assembly. The semantic triggers and constraints, applied by the students in case study 2 and reported in Table 2 clearly illustrate this. As reported in the result section, the changes and solutions found can be linked to the polarity of the affordance according to Gibson (1979) and to the types according to the classification made by Gaver (1991) in FA's, PA's, HA's or CR's. Based on the solutions implemented, the students were clearly capable of intuitively considering affordances and product semantics when designing a new product. Nevertheless, not all relevant affordances were considered (e.g., undesired assembly possibilities were still present in many products) and the semantics used were not always sufficient (e.g., were not capable of drawing the attention away from these undesired assembly possibilities). This was illustrated by the remaining 
problems in both case studies, as summarized in Table 1 and Table 2. Reconsidering RQ2, one can state that there is a clear difference between the solutions implemented by the students who redesigned a product compared to the teams who designed a new product. The teams that redesigned the product (case study 1), sought the solution more in product semantics (see Table 1). The teams that designed their products from scratch (case study 2), also considered constraints to alter affordances (see Table 2). This can be explained by the higher degree of freedom designers have when designing a new product. During a redesign it is not always possible to reconsider every aspect, every detail or every connection due to e.g., time limitations, budgets, etc. In case study 1 this was also the case, the teams only had 3 weeks to redesign their product and as a consequence considered how the goal of intuitive assembly could be reached most easily. Following, most of the teams in case study 1 decided to add elements (i.e., semantic triggers like colours, symbols, numbers, etc.) to their products to support correct assembly rather than to alter the constraints of the connections. These teams focused on promoting that the desired actions were perceptible (i.e., they focused on having desired perceptible affordances). In these solutions, the semantic changes have to trigger the attention towards the desired affordances so they potentially get perceived and interpreted. However, the other affordances, i.e., undesired PA's (e.g., allowing wrong assembly), FA's (triggering the operator to engage in an impossible action) and undesired HA's (undesired potential actions that are currently imperceptible) are still present in many products and can cause problems. These can especially cause problems when the semantic triggers are unclear to the operator or when they do not change the affordance threshold like desired. By raising or lowering the affordance threshold, affordances can become hidden or highlighted (Lu and Cheng, 2013). However, as reported in Table 1, this was not always a success. Analysis of the products and the assembly tests showed that in several products, correct assembly without procedural instructions was difficult and users engaged in actions that were undesired. Undesired perceptible affordances (-PA's), still present in these products, were an important problem as reported in Table 1. In case study 1, some teams did not change their product because it already promoted a clear mental model on how to assemble the product. These examples show that students carefully consider potential adaptations before changing their product. Other teams used clustering and spatial cueing like discussed by Kirsh (1995). This illustrates that students are able to consider affordances and semantics at other levels than the product. In case study 2, students were forced, due to the assignment, to consider at least two different assembly paths leading to two different functions in one product. As a consequence, sometimes two options of connecting components needed to be possible, and semantics were used to highlight the desired affordances during the assembly process. However, user tests also showed here some difficulties, semantics used to highlight a desired assembly path could become confusing when connections are shared between the two paths (e.g., using a different colour to indicate the connections in the different assembly paths when some connections are shared). These case studies were also subject to some limitations, i.e., different students, different products designed, different tolerances of components (the pieces were made with hand tools by the students), quality of the instruction, etc. In the case studies presented, products were designed with a focus on the end-user being able to assemble the product. However, in a production context, operators interact not only with components and subassemblies but also with tools, jigs, fixtures, the assembly environment itself, etc., and construct meaning from these different interactions. These additional interactions were not considered in the case-studies presented and form a limitation when considering a production context.

\section{CONCLUSION}

In case study 2 , where students designed a new product with a focus on a self-explaining assembly, solutions were clearly considered more in depth compared to case study 1 . In this second case study, students used physical constraints and product semantics to alter affordances or their perception. Nevertheless, both case studies illustrated that the teams were able to intuitively find solutions to promote self-explaining assembly, without following a particular framework, method or technique and without prior knowledge of affordance theory and product semantics. However, it also emerged that not all desired affordances were perceptible to the users. Moreover, undesired perceptible affordances and false affordances were still present in these products. Especially the presence of these undesired perceptible affordances (potentially leading to wrong assembly) and of hidden desired affordances (i.e., the desired action is not perceptible) are important attention points because they can both prevent correct 
assembly. These findings give an important argument to consider the development of a framework that supports the designer to consider design for meaning with a focus on self-explaining assembly, more systematically.

\section{REFERENCES}

Boess, S.U. (2008), "Meaning in product use: which terms do designers use in their work?", Proceedings of DeSForM, Offenbach, article, pp. 20-27.

Fast-Berglund, A.,, Fässberg, T., Hellman, F., Davidsson, A. and Stahre, J. (2013), "Relations between complexity, quality and cognitive automation in mixed-model assembly", Journal of Manufacturing Systems, The Society of Manufacturing Engineers, Vol. 32 No. 3, pp. 449-455. https://doi.org/10.1016/j.jmsy.2013.04.011

Gagné, M. and Deci, E.L. (2005), "Self-determination theory and work motiviation", Journal of Organizational Behavior, Vol. 26 No. 4, pp. 331-362. https://doi.org/10.1002/job.322

Gaver, W. (1991), "Technology affordances", Proceedings of the SIGCHI Conference on Human Factors in Computing Systems, ACM, available at: https://doi.org/10.1145/108844.108856.

Gibson, J.J. (1977), "The theory of affordances", in Shaw, R.E. and Bransford, J. (Eds.), Perceiving, Acting, and Knowing, Lawrence Erlbaum Associates.

Gibson, J.J. (1979), The Ecological Approach to Visual Perception., Boston, Houghton Miffin.

Johansson, P.E.C., Enofe, M.O., Schwarzkopf, M., Malmsköld, L., Fast-Berglund, ̊̊. and Moestam, L. (2017), "Data and Information Handling in Assembly Information Systems - A Current State Analysis", Procedia Manufacturing, Vol. 11, pp. 2099-2106. https://doi.org/10.1016/j.promfg.2017.07.335

Kirsh, D. (1995), “The intelligent use of space”, Artificial Intelligence, Vol. 73 No. 1-2, pp. 31-68. https://doi.org/10.1016/0004-3702(94)00017-u

Krippendorff, K. (1989), "Product semantics: A triangulation and four design theories", Product Semantic, University of Industrial Arts Helsinki.

Krippendorff, K. and Butter, R. (1984), "Product Semantics : Exploring the Symbolic Qualities of Form", Innovation, Vol. 3 No. 2, pp. 4-9.

Lu, J. and Cheng, L. (2013), "Perceiving and Interacting Affordances : A New Model of Human - Affordance Interactions", Integrative Psychological and Behavioral Science, Vol. 47 No. 1, pp. 142-155. https://doi.org/10.1007/s12124-012-9202-2

Norman, D. (1988), The Psychology of Everyday Things, book, Basic book, New York.

Norman, D. (1999), “Affordance, conventions, and design”, Interactions, Vol. 6 No. 3, pp. 38-43. https://doi.org/10.1145/301153.301168

Ryan, R.M. and Deci, E.L. (2000), "Self-determination theory and the facilitation of intrinsic motivation, social development, and well-being", American Psychologist, article, American Psychological Association, Vol. 55 No. 1, pp. 68-78. https://doi.org/10.1037//0003-066x.55.1.68

Sweller, J., Van Merrienboer, J.J.G. and Paas, F.G.W.C. (1998), "Cognitive Architecture and Instructional Design”, Educational Psychology Review, Vol. 10 No. 3, pp. 251-296. https://doi.org/10.1023/a:1022193728205

You, H., Chen, K. and Kung, N.C https://doi.org/10. (2007), "Applications of affordance and semantics in product design”, Design Studies, Vol. 28 No. 1, pp. 23-38. https://doi.org/10.1016/j.destud.2006.07.002 